\title{
Dystonia-aphonia syndrome
}

INSERM

\section{Source}

INSERM. (1999). Orphanet: an online rare disease and orphan drug data base. Dystoniaaphonia syndrome. ORPHA:412217

Dystonia-aphonia syndrome is a rare, genetic, persistent combined dystonia disorder characterized by slowly progressive, severe, caudo-rostrally spreading generalized dystonia with prominent facial and oro-mandibular involvement leading to severe anarthria and/or aphonia, swallowing difficulties, and gait disturbances. Additional manifestations include slowed horizontal saccades, subclinical epilepsy, photic myoclonus, oral hypertrophic changes (e.g. gingival or lingual hyperplasia), as well as delayed milestones and cognitive impairment. 